\title{
Kisspeptin antagonist prevents RF9-induced reproductive changes in female rats
}

\author{
Zafer Sahin $^{1}$, Sinan Canpolat ${ }^{1}$, Mete Ozcan $^{2}$, Tuba Ozgocer $^{3}$ and Haluk Kelestimur ${ }^{1}$ \\ ${ }^{1}$ Department of Physiology, Faculty of Medicine and ${ }^{2}$ Department of Biophysics, Medical School, Firat University, \\ Elazig 23119, Turkey and ${ }^{3}$ Department of Physiology, Medical School, Inonu University, Malatya, Turkey
}

Correspondence should be addressed to H Kelestimur; Email: hkelestimur@firat.edu.tr

\begin{abstract}
The aim of this study was to determine the modulatory effects of peptide 234 (p234) (an antagonist of GPR54 receptors) on kisspeptin and RF9 (an RFamide-related peptide antagonist)-induced changes in reproductive functions and energy balance in female rats. Female Sprague-Dawley rats were weaned on postnatal day (pnd) 21. The animals were intracerebroventricularly cannulated under general anesthesia on pnd 23. Groups of female rats were injected with kisspeptin, RF9, p234, kisspeptin plus p234, or RF9 plus p234, daily. The experiments were ended on the day of first diestrus following pnd 60. Kisspeptin or RF9 alone advanced vaginal opening (VO), which was delayed by administration of kisspeptin antagonist alone. In the rats given kisspeptin plus p234 or RF9 plus p234, VO was not different from control rats. Kisspeptin and RF9 elicited significant elevations in circulating LH levels. Coadministrations of kisspeptin or RF9 with p234 decreased LH levels significantly. The use of p234 alone did not cause any significant change in LH secretion. Kisspeptin decreased both food intake and body weight while RF9 decreased only food intake without affecting body weight. The effects of kisspeptin on energy balance were also reversed by central administration of p234. In conclusion, kisspeptin antagonist, p234, modulates the effects of kisspeptin on reproductive functions and energy balance, whereas RF9 seems to exert only its effects on reproductive functions by means of GPR54 signaling in female rats.

Reproduction (2015) 149 465-473
\end{abstract}

\section{Introduction}

During the last decade, our understanding of the hypothalamus-pituitary-gonadal (HPG) axis has quickly expanded. Two novel hypothalamic Arg-Phe-amiderelated peptides (RFRPs), kisspeptin (de Roux et al. 2003, Seminara et al. 2003) and gonadotropin-inhibitory hormone (GnlH) (Tsutsui et al. 2000, Kriegsfeld et al. 2006), are suggested to be important regulators of the reproductive axis. Kisspeptins are the natural ligands for the G protein-coupled receptor 54 (GPR54) (Kotani et al. 2001, Muir et al. 2001, Ohtaki et al. 2001), and mutations in GPR54 are associated with sexual immaturity and infertility in humans and rodents (Funes et al. 2003, de Roux et al. 2003, Seminara et al. 2003). Kisspeptins are termed kisspeptin 10, 13, 14, and -54 according to the number of amino acids in length, and the decapeptide kisspeptin 10, which is shared by all the members of kisspeptin family, is required for the biological activity (Kotani et al. 2001). Gonadotropinreleasing hormone $(\mathrm{GnRH})$ neurons have been shown to express GPR54 receptor (Parhar et al. 2004), through which kisspeptins activate GnRH secretion (Messager et al. 2005). In a recent study (Beale et al. 2014), kisspeptin knockdown in the arcuate nucleus (ARC) has been reported to result in a decrease in luteinizing hormone (LH) pulse frequency, which suggests that maintenance of ARC-kisspeptin levels is essential for normal pulsatile LH release and estrous cyclicity. Kisspeptin ( $d$ 'Anglemont de Tassigny et al. 2007) or Gpr54 knockout mice (Messager et al. 2005) are found to be infertile. Kisspeptins are reported to be the most potent activators of HPG axis known to date (Han et al. 2005). Central or peripheral administration of kisspeptin stimulates the gonadotropic axis (Matsui et al. 2004, Navarro et al. 2004, Thompson et al. 2004). Kisspeptins potently elicit $\mathrm{GnRH}$ release and $\mathrm{LH}$ secretion even at the pre-pubertal periods (Castellano et al. 2006). Chronic central administration of kisspeptin to immature female rats was shown to induce premature activation of the gonadotropic axis (Navarro et al. 2004), and peripheral injection of kisspeptin significantly increased plasma levels of LH (Thompson et al. 2004). In vitro studies also provide evidence that kisspeptins directly affect GnRH neurons (Kroll et al. 2011, Ozcan et al. 2011). Kisspeptin was demonstrated to increase the intracellular calcium concentration $\left[\mathrm{Ca}^{2+}\right]_{\mathrm{i}}$ in isolated GnRH neurons (Kroll et al. 2011) as well as in hypothalamic GT1-7 immortalized cell lines (Ozcan et al. 2011). Furthermore, GnRH secretion was increased 
in kisspeptin-activated GT1-7 cells (Jacobi et al. 2007, Novaira et al. 2009, Tonsfeldt et al. 2011). Taken together, these findings implicate an important role for kisspeptin/GPR54 for the regulation of sexual maturation and the development of the reproductive system.

GnlH was first discovered in birds (Tsutsui et al. 2000, Kriegsfeld et al. 2006). Orthologous peptides belonging to RFRP superfamily were then found in mammals (Smith \& Clarke 2010). RFRP-3 inhibits gonadotropin secretion in mammals (Johnson et al. 2007). RFRP functions as GnIH, inhibiting gonadotropin-releasing hormone-stimulated gonadotropin mRNA subunits and $\mathrm{LH}$ release (Son et al. 2012). Initially, only GnIH and RFRP-3 were considered to be functional homologs (Tsutsui 2009) because RFRP-1 was found to only affect prolactin secretion (Hinuma et al. 2000). More recently, however, RFRP-1 has been shown to affect LH secretion (Ubuka et al. 2012). RFRP-3 may also directly modulate GnRH because RFRP-3 immunoreactive neurons have been shown to form close appositions with $\mathrm{GnRH}$ neurons in rodents and humans (Johnson et al. 2007, Ubuka et al. 2009). Electrophysiological recordings of mouse brains reveal that $\mathrm{GnIH}$ and RFRP have inhibitory actions on GnRH neurons (Ducret et al. 2009, Wu et al. 2009). These studies suggest that GnlH and RFRP-3 may regulate HPG axis. However, the physiological role played by RFRP-3 in the control of HPG system remains yet to be fully elucidated.

There is growing evidence that RFRPs show their effects on reproductive functions by modulating kisspeptin/GPR54 signaling system. Our previous experiment (Kelestimur et al. 2013) shows that GnlH treatment attenuates kisspeptin 10-induced $\mathrm{GnRH}$ release in GT1-7 cells. Combined injection of kisspeptin 10 and the antagonist of RFRP receptor, RF9, modestly increased the responses to kisspeptin alone (Pineda et al. 2010a). The above data strongly suggest the possibility of interactions between kisspeptins and RFRP in the control of the HPG axis. Therefore, it is proposed that it is the dynamic balance and interplay between these two sets of factors that drives the function of the reproductive system (Kriegsfeld et al. 2006).

Recent studies have suggested that kisspeptin signaling plays a key role in the interaction between metabolic status and reproduction. Kisspeptin neurons are relatively well known to mediate metabolic effects on reproductive status (De Bond \& Smith 2014, Roa \& Tena-Sempere 2014). Adult female mice lacking kisspeptin signaling (kiss1r KO) displayed dramatically higher body weight (Tolson et al. 2014), which also suggests that kisspeptin signaling also plays a reciprocal role in regulating energy and metabolic status. The modulatory effects of RFRP on kisspeptin are important in terms of not only reproductive functions but also nutritional aspects. For example, functional electrophysiological analyses have documented the ability of RFRP-3 to inhibit the excitatory actions of kisspeptins on pro-opiomenalocortin (POMC) neurons (Fu \& van den Pol 2010). Therefore, in the present experiment, the importance of the interaction between kisspeptin and RFRP was also investigated in terms of energy metabolism.

Briefly, the studies presented had two objectives. The first aim was to investigate whether the GnIH/RFRP-3 receptor antagonism has modulatory effects on pubertal maturation. To test this possibility, RF9, a selective antagonist of RFRP receptors, was prepubertally given to the rats. The second objective was to confirm whether kisspeptin/GPR54 system is necessary for RF9 to show its effects. To test this concept, peptide 234 (p234), a kisspeptin antagonist, was prepubertally given to the animals. All these studies will contribute to the pubertal sensitivity degree of kisspeptin/GPR54 system to RFRP-3 effects.

The understanding of the effects of kisspeptin and RFRP-3 antagonists will not only contribute to the delineation of the roles of the endogenous kisspeptin and RFRP systems in the neuroendocrine regulation of the gonadotropic system and energy metabolism, but also provide new therapeutic approaches to treat some hormone-dependent reproductive and metabolic disorders such as precocious puberty and obesity respectively.

\section{Materials and methods}

\section{Animals and drugs}

Prepubertal Sprague-Dawley female rats, aged 21 days and weighing $40 \pm 2 \mathrm{~g}$, were obtained from the University of Firat Experimental Research Unit (Elazig, Turkey). The experimental protocols were approved by Firat University Ethical Committee, and the rats were treated in accordance with the national and international laws and policies on the care and use of laboratory animals. The animals were weaned at day 21 postpartum and were housed under standard light/darkness schedule (12 h light:12 h darkness from $0700 \mathrm{~h}$ ), at constant temperature $\left(21 \pm 1{ }^{\circ} \mathrm{C}\right)$ and humidity (55 $\pm 5 \%$ ) with free access to pelleted food and tap water. Kisspeptin 10 (45-54), RF9, and p234 were obtained from Sigma. They were freshly prepared in saline on the experiment day.

\section{Experimental design}

All animals were fitted with a stainless steel cannula positioned according to stereotaxical coordinates (Paxinos \& Watson 1998) into the lateral ventricle of the brain via a hole drilled in the skull $1.5 \mathrm{~mm}$ lateral and $1 \mathrm{~mm}$ posterior to bregma; the cannula was fixed at a depth of $3.2 \mathrm{~mm}$ from the skull surface at postnatal day (pnd) 23. Surgery was performed under general anesthesia with xylazine $(80 \mathrm{mg} / \mathrm{kg}) / \mathrm{ketamine}(12 \mathrm{mg} / \mathrm{kg})$ cocktail. Post-operatively, the rats received analgesia for 2 days by an oral dose of ibuprofen 1 (1 mg/rat) and their health condition was frequently checked.

The rats were divided into six groups ( $n=7$ for each group). Sham controls received saline only $(5 \mu \mathrm{l})$. This group will be referred as 'vehicle'. Experimental groups were designed as kisspeptin, p234, kisspeptin plus p234, RF9, and RF9 plus 
p234. Peptides were administrated to animals by an i.c.v. bolus injection between 1000 and $1200 \mathrm{~h}$ from pnd 26 to pnd 60 . Doses of 50 pmol kisspeptin, 1 nmol p234, and 10 nmol RF9 (in $5 \mu \mathrm{l} / \mathrm{rat}$ ) were performed.

From pnd 26 to pnd 60 , along treatment, the animals were monitored for daily food and water intake and body weight gain. Vaginal opening (VO), a morphological sign of the puberty, was evaluated from pnd 26 to puberty. Sexual cycle was detected by daily vaginal cytology after the occurrence of vaginal canalization. The experiment ended after pnd 60 . On the afternoon of the first diestrus following 60 days, blood was taken for $15 \mathrm{~min}$ by decapitation after last i.c.v. injection. Ovarian and uterine tissues were dissected out and weighed at the end of treatment. The cannula position was checked at autopsy. Only the rats with the cannula correctly positioned in the lateral ventricle of the brain were included.

\section{Hormone measurements}

Serum $\mathrm{LH}$ and follicle-stimulating hormone $(\mathrm{FSH})$ were analyzed briefly as follows. Immunoplates (96-well) (Nunc, Roskilde, Denmark) were coated with rat LH or FSH. Serum samples or standards were preincubated with primary antibodies and were then transferred into coated plates for competition with antigens on the solid phase. Plates were washed and the secondary antibody conjugated to streptavidin peroxidase was added into each well and color was developed using tetramethylbenzidine as the substrate. Plates were read at an absorbance of $450 \mathrm{~nm}$ using a plate reader (Biotek Synergy HT, Winooski, VT, USA). Rat $\mathrm{LH}$, rat $\mathrm{FSH}$, and primary antibodies (rabbit anti-rat $\mathrm{LH}$ and rabbit anti-rat FSH) were obtained from Dr A F Parlow (National Institute of Diabetes and Digestive and Kidney Diseases National Hormone and Peptide Program, National Institutes of Health, USA) and secondary antibodies (goat anti-rabbit IgG) conjugated to streptavidin peroxidase was purchased from Sigma-Aldrich. Sensitivity of the assays was $1 \mathrm{ng} / \mathrm{ml}$ for $\mathrm{LH}$ and $2 \mathrm{ng} / \mathrm{ml}$ for FSH. Inter- and intra-assay coefficient of variation values were below $8 \%$ for both $\mathrm{LH}$ and $\mathrm{FSH}$.

Serum leptin levels were measured using a commercial rat ELISA kit (Merck KGaA). The inter- and intra-assay coefficient of variation values were $3.0-3.9$ and $1.9-2.5 \%$ respectively.

\section{Presentation of data and statistical analysis}

Hormonal determinations were carried out in duplicate, with a minimal total number of seven samples per group and values are expressed as mean \pm s.E.M. Results were analyzed using one-way ANOVA followed by post-hoc Tukey's honestly significant difference (HSD) test. For all analyses, $P<0.05$ was considered statistically significant.

\section{Results}

\section{Central administration of p234 inhibits kisspeptin- induced pubertal advancement and $\mathrm{LH}$ increase in the female rats}

I.c.v. administration of kisspeptin advanced VO compared with sham rats $(33.6 \pm 0.8$ days vs $38.1 \pm 0.8$ days respectively). While all of the animals injected with kisspeptin showed complete canalization of vagina on 34 days, none of the females treated with vehicle presented complete VO at the same age (Fig. 1A). We used p234, the kisspeptin receptor antagonist, for pharmacological characterization of the kisspeptin-induced advancement in timing of puberty. I.c.v. administration of kisspeptin antagonist p234 delayed the timing of puberty (40.8 \pm 0.7 days), and $85.8 \%$ of animals infused only p234 displayed complete canalization of vagina on 41 days. In the rats administered kisspeptin and p234 together, puberty onset was similar to sham rats $(36.9 \pm 1.1$ days vs $38.1 \pm 0.8$ days respectively; Fig. 1A). Pubertal weight was found to be lower $(P<0.05)$ in the kisspeptin-injected rats compared with sham rats $(66.7 \pm 3.8$ and $86.4 \pm 5.4 \mathrm{~g}$ respectively; Fig. $1 \mathrm{~B})$. The i.c.v. administration of p234 alone did not affect pubertal weight values compared with sham rats $(86.9 \pm 2.6$ and $86.4 \pm$ $5.4 \mathrm{~g}$ respectively). When the effects of administration of
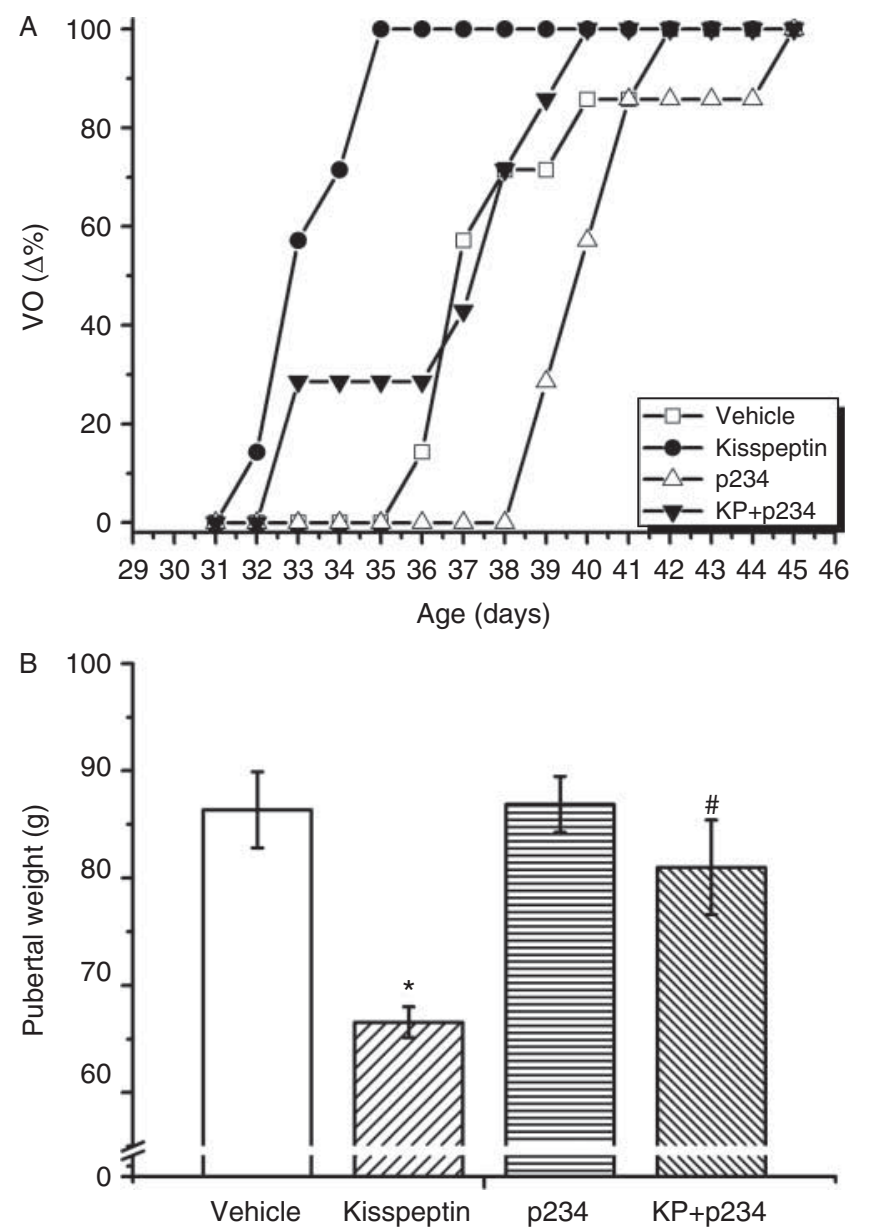

Figure 1 Effects of i.c.v. injection of kisspeptin, p234, and kisspeptin plus p234 on different indices of puberty onset are documented in female rats (pnd 26-60) (A) vaginal opening (B) pubertal weights are presented for animals treatment with vehicle, kisspeptin, p234 and kisspeptin plus $2234,{ }^{*} P<0.05$; vs control (vehicle) group, ${ }^{\#} P<0.05$; vs kisspeptin group (one-way ANOVA followed by post-hoc Tukey's HSD test), $n=7$ for each group. KP, kisspeptin; VO, vaginal opening. 
kisspeptin plus p234 were tested, pubertal weight was significantly increased to $81.0 \pm 4.4 \mathrm{~g}$ compared with kisspeptin-treated group ( $P<0.05$, Fig. 1B).

Although not statistically significant, the uterine weights of kisspeptin-treated group tended to be higher than the vehicle group $(165.2 \pm 18.9$ and $150.1 \pm 6.9 \mathrm{mg} / 100 \mathrm{~g}$ respectively; Fig. 2A). When the effects of p234-treated group were tested, uterine weight was reduced to $115.2 \pm 13.1 \mathrm{mg} / 100 \mathrm{~g}$ compared with the vehicle group $(P<0.05$, Fig. 2A). Uterine weight was not statistically affected by kisspeptin plus p234 compared with vehicle group $(138.7 \pm 10.4$ and $150.1 \pm 6.9 \mathrm{mg} / 100 \mathrm{~g}$ respectively; Fig. 2A). Moreover, the results revealed no significant difference between kisspeptin-treated group and vehicle group in ovarian weights $(48.3 \pm 2.1$ and $58.8 \pm 1.7 \mathrm{mg} /$ $100 \mathrm{~g}$ respectively; Fig. 2A). When the effects of p234-treated group were tested, the ovarian weight was reduced to $38.7 \pm 3.8 \mathrm{mg} / 100 \mathrm{~g}$ compared with the vehicle group $(P<0.05$, Fig. $2 \mathrm{~A})$. Ovarian weights were not significantly affected by kisspeptin plus p234 compared with vehicle group $(49.5 \pm 0.9$ and $58.8 \pm$ $1.7 \mathrm{mg} / 100 \mathrm{~g}$ respectively; Fig. 2A).

The significant difference in the mean LH level was detected between kisspeptin-treated and vehicle groups $(8.3 \pm 0.6$ and $4.3 \pm 0.3 \mathrm{ng} / \mathrm{ml}$ respectively, $P<0.01)$. LH levels of p234-treated group were similar to sham rats $(4.1 \pm 0.5$ and $4.3 \pm 0.3 \mathrm{ng} / \mathrm{ml}$ respectively). The $\mathrm{LH}$ level was significantly affected by kisspeptin plus p234 compared with kisspeptin-treated group $(4.7 \pm 0.5$ and $8.3 \pm 0.6 \mathrm{ng} / \mathrm{ml}$ respectively, $P<0.05$, Fig. $2 \mathrm{~B}$ ). No overt differences in FSH levels were determined between vehicle and kisspeptin-treated groups $(3.6 \pm 0.1$ and $4.2 \pm 0.4 \mathrm{ng} / \mathrm{ml}$ respectively; Fig. $2 \mathrm{~B}$ ). FSH levels of p234-treated group were similar to those of sham rats $(3.6 \pm 0.2$ and $3.6 \pm 0.1 \mathrm{ng} / \mathrm{ml}$ respectively; Fig. $2 \mathrm{~B})$.

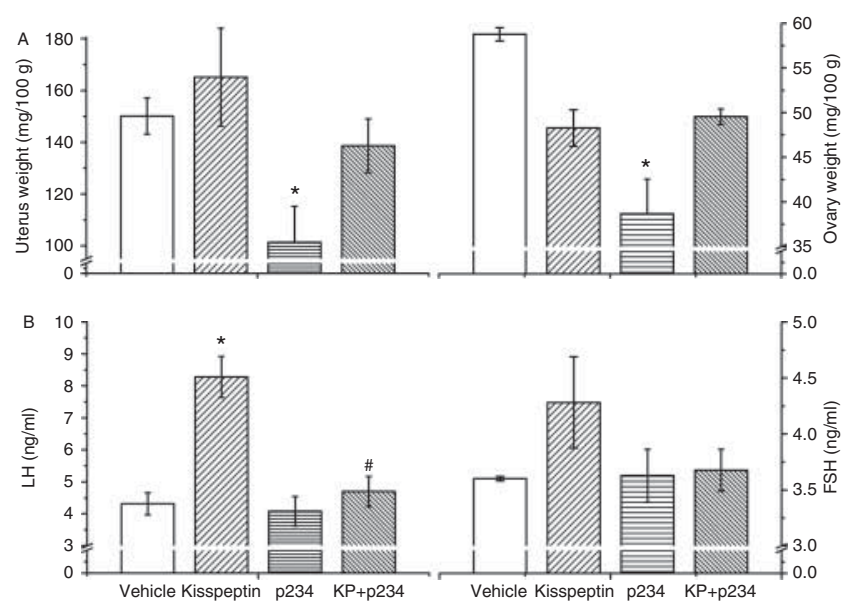

Figure 2 Effects of i.c.v. injection of kisspeptin, p234, and kisspeptin plus p234 on uterus weight, ovary weight, $\mathrm{LH}$, and FSH levels in female rats. Note that scales are different for uterus and ovary weight, $\mathrm{LH}$ and FSH levels. ${ }^{*} P<0.05$; vs control (vehicle) group, ${ }^{\sharp} P<0.05$; vs kisspeptin group (one-way ANOVA followed by post-hoc Tukey's HSD test), $n=7$ for each group.
There was no statistically significant difference between kisspeptin plus p234 group and vehicle group in $\mathrm{FSH}$ levels ( $3.7 \pm 0.2$ and $4.2 \pm 0.4 \mathrm{ng} / \mathrm{ml}$ respectively; Fig. $2 \mathrm{~B})$.

\section{Central administration of p234 inhibits RF9-induced pubertal advancement and increase in $\mathrm{LH}$ levels in female rats}

I.c.v. administration of RF9 advanced VO compared with sham rats $(35.1 \pm 0.9$ days vs $38.1 \pm 0.8$ days respectively). While all of the animals injected with RF9 showed complete canalization of vagina on 37 days, $57.2 \%$ of the females treated with vehicle presented complete $\mathrm{VO}$ at the same age (Fig. 3A). The pubertyaccelerating effect of RF9 was blocked by p234. In the rats given RF9 and p234 together, puberty onset was similar to sham rats $(36.2 \pm 2.3$ days vs $38.1 \pm 0.8$ days respectively; Fig. $3 \mathrm{~A}$ ).

Although not statistically significant, pubertal weight was found to be lower in the RF9-injected rats compared with sham rats $(77.8 \pm 2.3$ and $86.4 \pm 5.4$ g respectively; Fig. 3B). When the effects of administration of RF9 plus p234 were tested, pubertal weight was not significantly changed to $83.6 \pm 2.9 \mathrm{~g}$ compared with RF9 alonetreated group (Fig. 3B).

In the rats administered RF9, uterine weights were similar to sham rats $(150.2 \pm 14.9$ and $150.1 \pm$ $6.9 \mathrm{mg} / 100 \mathrm{~g}$ respectively). Uterine weights were not significantly affected by RF9 plus p234 compared with vehicle group $(142.2 \pm 12.9$ and $150.1 \pm 6.9 \mathrm{mg} / 100 \mathrm{~g}$ respectively; Fig. 4A). Moreover, the results revealed no significant difference between RF9-treated and vehicle groups in the ovarian weights $(49.2 \pm 3.0$ and $58.8 \pm$ $1.7 \mathrm{mg} / 100 \mathrm{~g}$ respectively; Fig. 4A). The ovarian weights were not significantly affected by RF9 plus p234 compared with vehicle group $(43.8 \pm 1.1$ and $58.8 \pm$ $1.7 \mathrm{mg} / 100$ g respectively; Fig. 4A).

The differences in mean LH levels were detected between RF9-treated and vehicle groups $(7.7 \pm 0.7$ and $4.3 \pm 0.3 \mathrm{ng} / \mathrm{ml}$ respectively, $P<0.01$ ). There was a significant difference between RF9 plus p234 group and RF9 group in LH levels $(5.1 \pm 0.3$ and $7.7 \pm$ $0.7 \mathrm{ng} / \mathrm{ml}$ respectively, $P<0.05$, Fig. $4 \mathrm{~B})$. The differences in mean FSH levels were not detected between RF9-treated and vehicle groups $(4.4 \pm 0.1$ and $4.2 \pm$ $0.4 \mathrm{ng} / \mathrm{ml}$ respectively; Fig. 4B). Moreover, no overt differences in FSH levels were determined between RF9 plus p234-treated and RF9-treated groups $(4.2 \pm 0.1$ and $4.2 \pm 0.4 \mathrm{ng} / \mathrm{ml}$ respectively; Fig. 4B).

\section{Central administration of p234 inhibits both kisspeptin and RF9-induced food intake and body weight reductions}

Animals were monitored for daily water, food intake and percentage of body weight change from pnd 26 to pnd 60 . There were no any significant changes between the 


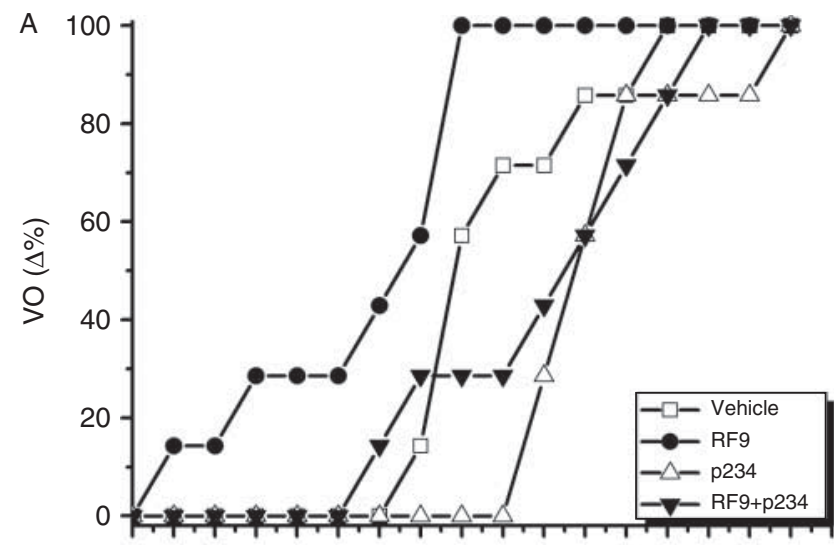

293031323334353637383940414243444546 Age (days)

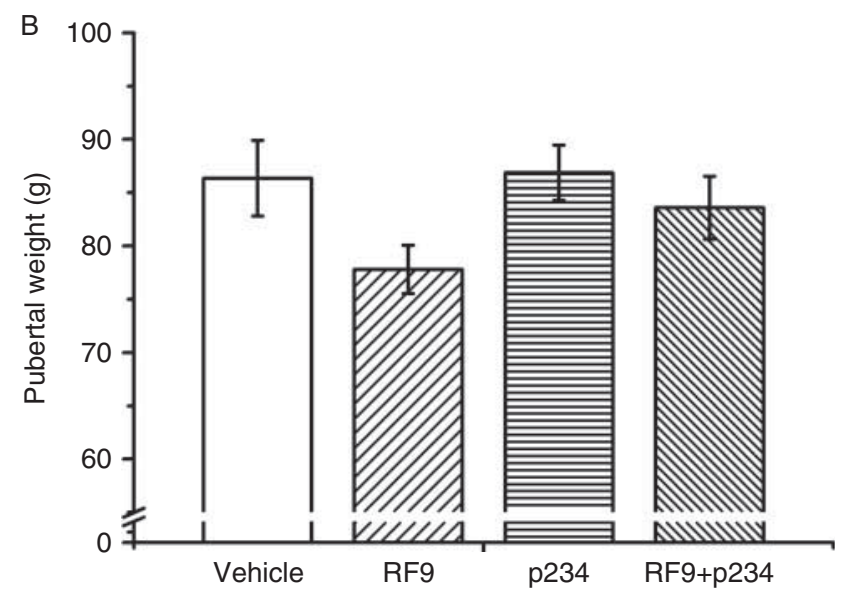

Figure 3 Effects of i.c.v. injection of RF9, p234, and RF9 plus p234 on different indices of puberty onset are documented in female rats (pnd 26-60) (A) vaginal opening, (B) pubertal weights are presented for animals treated with vehicle, RF9, p234, and RF9 plus p234, $n=7$ for each group. $\mathrm{VO}$, vaginal opening.

groups in terms of water intake. When compared with vehicle group, although not significant, water intake of RF9-treated group was slightly lower (Fig. 5D).

Food intake from pnd 30 to pnd 45 was significantly lower in kisspeptin-treated group compared with vehicle group $(P<0.05$, Fig. 5B), while food intake was not significantly affected by administration of p234 compared with vehicle group. Interestingly, the reducing effect of kisspeptin on food intake was blocked by p234 (Fig. 5B). Food intake was significantly lower in RF9 group compared with the vehicle group from pnd 42 to pnd $60(P<0.05$, Fig. 5E). The reducing effect of RF9 on food intake was slightly affected by p234 (Fig. 5E).

There was a significant difference in the percentage of body weight change between kisspeptin-treated and vehicle groups from 28 days to 60 days $(P<0.05$, Fig. 5C). p234 did not cause any significant change in the percentage of body weight change compared with the vehicle group. The reducing effect of kisspeptin on the percentage of body weight change was inhibited by p234 (Fig. 5C). However, in RF9 and RF9 plus p234 groups, the percentages of body weight change were similar to the vehicle group (Fig. 5F). There were no any significant changes between the groups in terms of serum leptin levels (Table 1).

\section{Discussion}

Although kisspeptin has been well known to play key roles in reproductive functions including pubertal maturation for the last decade, the lack of adequate antagonists blocking kisspeptin signaling has made it difficult to explore the actual role of endogenous kisspeptin in reproductive and any other related physiological functions. The first antagonist namely p234 has been discovered (Roseweir et al. 2009) and very useful for understanding of the physiological roles of kisspeptin. In this study, we investigated whether p234 modulates the central effects of kisspeptin 10 and RF9 on the pubertal maturation and energy metabolism in the female rats. We demonstrate in this study that p234 reverses the pubertal-advancement effects of kisspeptin 10 and RF9. Central administration of p234 also reverses kisspeptin and RF9-induced LH secretion. While we observed significant effects on $\mathrm{LH}$ secretion, FSH did not significantly change in the p234-treated rats. While the reverse effects of p234 on LH secretion in kisspeptintreated animals are investigated by other researchers (Pineda et al. 2010b), this study was the first to test whether p234 is able to prevent pubertal advancement and $\mathrm{LH}$ increase due to administration of RF9. This experimental model would provide additional evidence that RF9 shows its effects by modulating the kisspeptin/ GPR54 signaling system.
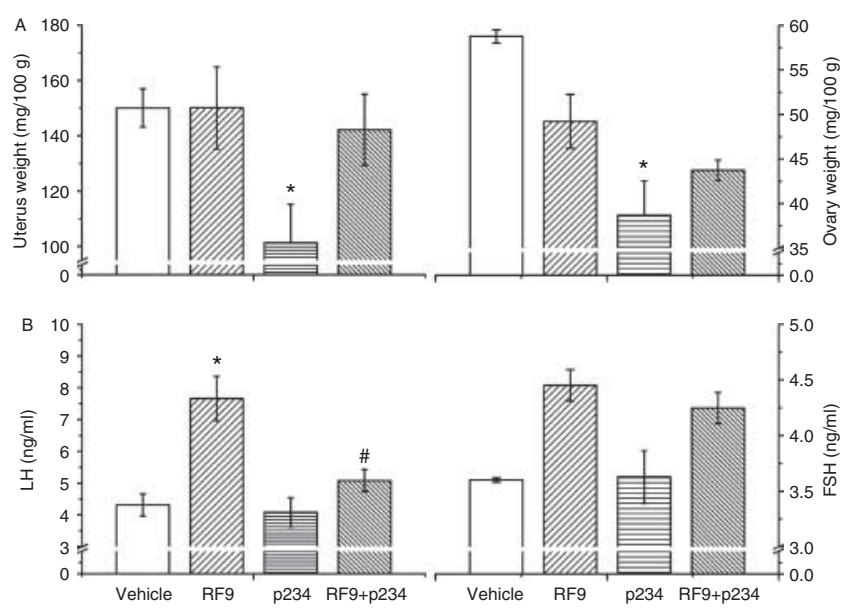

Figure 4 Effects of i.c.v. injection of RF9, p234, and RF9 plus p234 on uterus weight, ovary weight, $\mathrm{LH}$, and FSH levels in female rats. Note that scales are different for uterus and ovary weight, $\mathrm{LH}$ and $\mathrm{FSH}$ levels. ${ }^{*} P<0.05$; vs control (vehicle) group, ${ }^{*} P<0.05$; vs RF9 group (one-way ANOVA followed by post-hoc Tukey's HSD test), $n=7$ for each group. 

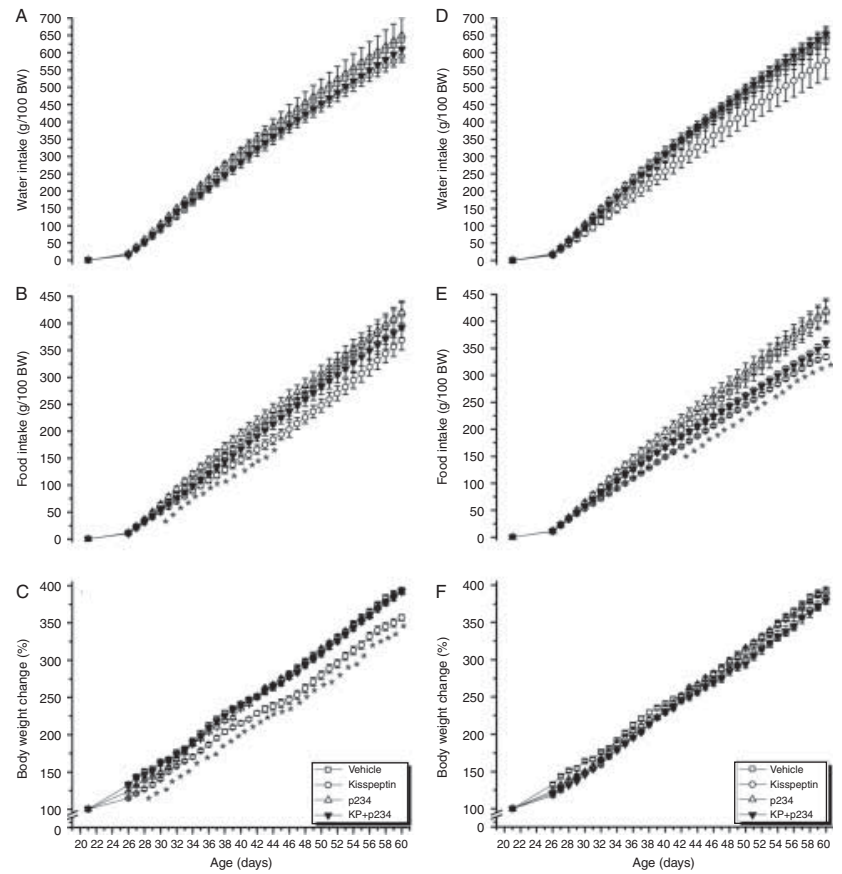

Figure 5 Effects of i.c.v. injection of kisspeptin, p234, kisspeptin plus p234, RF9, and RF9 plus p234 on different indices of energy balance are documented in female rats (26-60 days). (A and $D)$ Water intake, (B and $\mathrm{E}$ ) food intake, and ( $\mathrm{C}$ and $\mathrm{F}$ ) body weight change (\%). ${ }^{*} \mathrm{P}<0.05$; vs control (vehicle) group (one-way ANOVA followed by post-hoc Tukey's HSD test). $n=7$ for each group. BW, body weight.

\section{Central administration of p234 inhibits kisspeptin- induced pubertal advancement and $L H$ increase in the female rats}

To study the role of kisspeptin in the regulation of puberty, kisspeptin and kisspeptin antagonist (p234) either alone or in combination were centrally administered to the pre-pubertal female rats. Our finding that central administration of kisspeptin to immature female rats advanced puberty onset is consistent with other studies (Navarro et al. 2004). However, in our study, a lower i.c.v. dose $(50 \mathrm{pmol})$ and earlier administration (from pnd 23) were performed while kisspeptin 10 was used at the dose of $1 \mathrm{nmol} / 12 \mathrm{~h}$ and from 26 days in that study (Navarro et al. 2004). Thus, kisspeptin has been shown to advance puberty onset even at such a low dose. The rats receiving only p234 delayed VO significantly. p234 also prevented the rats from showing pubertal advancement resulting from kisspeptin administration. This result is the first to show the effects of i.c.v. kisspeptin antagonist on puberty response to i.c.v. kisspeptin. Dramatic suppression of VO by i.c.v. injection of kisspeptin antagonist alone and prevention of pubertal advancement response to kisspeptin provide strong evidence that kisspeptin/GPR54 signaling system is very sensitive in the prepubertal period. While the other studies used kisspeptin antagonist alone and reported its puberty-delaying effect, we used p234 together with kisspeptin in the present experiment. Thus, this is the first time to show that the pubertal accelerating effect of central administration of kisspeptin to immature female rats was reversed by kisspeptin antagonist. Therefore, p234 has the potential to be used to treat precocious puberty caused by increased activation of kisspeptin receptor (Fig. 1).

The other interesting finding in the present experiment was that pubertal weight was lower in kisspeptin-treated rats, which was reversed by the administration of p234. In one study (Navarro et al. 2004), central administration of kisspeptin was reported not to cause any significant change in pubertal weight despite pubertal advancement. Pubertal weight has also been reported not to change despite delayed puberty due to administration of kisspeptin antagonist to female rats (Pineda et al. 2010 b). The different findings in our study may result from very early administration of kisspeptin at a low dose. Our finding indicates that the puberty-accelerating effect of exogenous kisspeptin occurs independently of body weight.

LH secretory response to i.c.v. administration of kisspeptin was reduced by administration of kisspeptin antagonist, whereas FSH response to i.c.v. administration of kisspeptin was not as obvious as the $\mathrm{LH}$ response. Kisspeptin antagonist also reduced $\mathrm{FSH}$ response at a nonsignificant level. It has been reported that despite the inhibition of hormonal surges, basal LH and FSH levels are not overtly decreased by administration of the antagonist in cyclic females (Pineda et al. 2010b). Our finding supports this concept because LH levels in diestrus were significantly lowered only by coadministration of kisspeptin and p234, which indicates that p234 alone has no inhibitory effect on the basal gonadotropic input to the gonads. p234 has been shown to inhibit the kisspeptin-induced release of $\mathrm{LH}$ in male rats (Roseweir et al. 2009). Our finding in female rats is consistent with the results obtained from that study conducted in male animals. In good agreement with a marked delay in the timing of puberty, i.c.v. administration of p234 caused a significant reduction in ovarian and uterine weights at the end of treatments. These findings concur with the data from another study using female rats (Pineda et al. 2010b).

Table 1 Effects of i.c.v. injection of kisspeptin, P234, kisspeptin plus P234, RF9, and RF9 plus P234 on serum leptin levels in the female rats ( $n=7$ for each group).

\begin{tabular}{lc}
\hline Groups & Serum leptin levels $(\mathrm{ng} / \mathrm{ml})$ \\
\hline Vehicle & $0.19 \pm 0.02$ \\
Kisspeptin & $0.19 \pm 0.02$ \\
p234 & $0.15 \pm 0.03$ \\
KP+p234 & $0.16 \pm 0.01$ \\
RF9 & $0.16 \pm 0.02$ \\
RF9+p234 & $0.20 \pm 0.00$ \\
\hline
\end{tabular}




\section{Central administration of p234 inhibits RF9-induced pubertal advancement and increase in $\mathrm{LH}$ levels in female rats}

In the second part of the experiment, the interaction between p234 and RF9 was investigated. Although RF9 was developed as an antagonist of neuropeptide FF receptors (NPFFR), GPR147 and GPR74, that are activated by RFRP-3 and many other neuropeptides (Simonin et al. 2006), it has been demonstrated that administration of RF9 augmented the gonadotropinreleasing effects of kisspeptin (Pineda et al. 2010a), and the activation of GnRH neurons by RF9 is dependent upon kisspeptin receptor expression (Liu \& Herbison 2014). Among the reported NPFFR ligands, RF9 has been found to show significantly low affinity with GPR54 (Simonin et al. 2006). The bioactivity of NPFFR ligands for GPR54 has been shown to have an opposite crossreactivity because GPR54 ligands exhibit cross-reactivity for NPFFRs (Oishi et al. 2010), which suggest that RF9 may have direct effects on kisspeptin receptor. I.v. administration of RF9 has been recently reported to prevent the reduction in the levels of testosterone resulting from fasting conditions in male monkeys (Batool et al. 2014). The underlying mechanisms by which RF9 exerts its effects on reproductive functions remain yet to be determined. Therefore, in the present experiment, we tried to explore whether kisspeptin receptor antagonism affects the reproductive responses to RF9. In the present experiment, p234 inhibited advancement of puberty caused by RF9, which was the same response as to kisspeptin-induced pubertal acceleration. This finding provides further evidence for a role of GPR54 signaling in RF9 excitation of pubertal maturation. In keeping with other studies (Pineda et al. 2010a), in the current study, central injection of RF9 evoked an increase in circulating $\mathrm{LH}$ levels in the female rats, and contrarily, there were no significant modifications of serum FSH concentrations, which were similar response to central administration of RF9 to mice (García-Galiano et al. 2012). Our data show for the first time the role of kisspeptin antagonist in mediating the effects of RF9 on puberty onset and LH secretion, thus supporting the hypothesis that RF9 actions on reproductive functions are indirectly mediated via kisspeptin/GPR54 signaling in female rats. It has been reported that the $\mathrm{GnRH}$ release in response to kisspeptin occurs only in a portion (50\%) of brain slices from mice at 1 and 2 weeks of age, whereas RF9 had a consistent effect to increase $\mathrm{GnRH}$ release in $100 \%$ of preparations tested at 2 weeks of age (Glanowska et al. 2014). Therefore, it has been suggested that there is an additional caveat beyond RF9 acting at both GPR147 and GPR74 that is important to consider, and it is possible that RF9 has off-target actions as an agonist on a stimulatory receptor as similarities in C-terminal structure of $\mathrm{GnIH}$ with kisspeptin might indicate the kisspeptin receptor as a possible target, which is consistent with our findings.
Finally, we can postulate that RF9 does not only block $\mathrm{GnIH}$ receptors but also activate kisspeptin receptors.

\section{Central administration of p234 inhibits kisspeptin- induced food intake and body weight reductions}

In the present experiment, we looked at the effects of kisspeptin antagonism on the food intake and body weight responses to kisspeptin and RF9 treatments. Central administrations of both kisspeptin and RF9 reduced food intake significantly at different times. While kisspeptin decreased food intake between 30 and 45 days, RF9 showed its effects on food intake from 42 days to 60 days when the experiment ended. Kisspeptin caused significant reductions in body weight throughout the experiment, whereas RF9 did not have a significant effect on body weight. Central administration of p234 to the female rats inhibited decreases in food intake and body changes resulting from kisspeptin administration. Kisspeptin antagonist did not reverse RF9-induced decrease in food intake completely.

The studies on the effects of kisspeptin on food intake and body weight are controversial. A recent study (Tolson et al. 2014) has demonstrated that kisspeptin signaling has a potential to become an important and novel regulator of energy metabolism besides governing reproduction. In that study, adult female mice lacking kisspeptin signaling (Kiss1r KO) displayed dramatically higher body weight, leptin levels, and adiposity, along with strikingly impaired glucose tolerance. Surprisingly, despite their obesity, Kiss1r KO females ate less than WT females. The finding that Kiss $1 \mathrm{r} \mathrm{KO}$ mice have decreased food intake despite increased body weight (Tolson et al. 2014) is not consistent with our data. In the current experiment, kisspeptin has been shown to affect food intake only in younger female rats, whereas adult female mice have been found to have decreased food intake. Our finding that central administration of kisspeptin decreased food intake between 30 and 45 days means that anorectic effect of kisspeptin is observed especially during pubertal period. Therefore, the effect of kisspeptin on food intake seems to weaken in older age. In keeping with our finding, there was no effect of kisspeptin on food intake in sheep (Clarke et al. 2012). While central kisspeptin administration has been initially reported not to have any significant effects on food intake and body weight in rats (Castellano et al. 2005), central administration of kisspeptin has been recently shown to increase meal intervals, resulting in a decrease in nocturnal food intake in mice (Stengel et al. 2011). There is strong evidence that kisspeptin would decrease food intake and increase energy expenditure, resulting in a decrease in body weight. In one electrophysiological study, kisspeptin has been shown to directly excite POMC/ CART neurons and indirectly inhibit NPY/AgRP neurons (Fu \& van den Pol 2010). Our finding that central administration of kisspeptin causes decreases in food intake and body weight is consistent with the results of this 
electrophysiological study. In the present experiment, the excitatory effect of kisspeptin antagonist on food intake shows that the central anorectic effect of kisspeptin is dependent upon kisspeptin receptor. Our finding is consistent with the observation that NPY/AgRP and POMC/CART neurons receive afferent fibers from kisspeptin neuron (Backholer et al. 2010). The finding that there were no any significant changes between the groups in terms of serum leptin levels reveals that the effects of kisspeptin and kisspeptin antagonist on energy metabolism are independent of leptin secretion.

RF9 had been previously proposed as potential drug treatment for improving the efficacy of opioids in the management of chronic pain because RF9 completely blocks the delayed and long-lasting paradoxical opioidinduced hyperalgesia and prevents the development of associated tolerance (Simonin et al. 2006). I.c.v. administration of RF9 has been recently reported to cause a dose-dependent anorexigenic effect in male mice (Maletinská et al. 2013). In that experiment, the anorexigenic effect of RF9 was found only with a dose of $30 \mathrm{nmol}$. We provide in this study the first demonstration that RF9 has a strong food intake-suppressing effect in female rats with as low as $1 \mathrm{nmol}$. Our finding is indirectly in keeping with the data that GnIH-3 (RFRP-3) increases food intake in mammals without reducing energy expenditure (Clarke et al. 2012).

In conclusion, it is possible that kisspeptin/GPR54 signaling may play additional roles in energy balance beyond the control of reproduction, and may also be important in the regulation of reproductive functions by RF9. We also provide further evidence that RF9 possesses appetite-suppressing action. These observations not only are of physiological interest, but also have potential pharmacological implications.

\section{Declaration of interest}

The authors declare that there is no conflict of interest that could be perceived as prejudicing the impartiality of the research reported.

\section{Funding}

This work was supported by TUBITAK-113S193.

\section{References}

d'Anglemont de Tassigny X, Fagg LA, Dixon JP, Day K, Leitch HG, Hendrick AG, Zahn D, Franceschini I, Caraty A, Carlton MB et al. 2007 Hypogonadotropic hypogonadism in mice lacking a functional Kiss1 gene. PNAS 104 10714-10719. (doi:10.1073/pnas.0704114104)

Backholer K, Smith JT, Rao A, Pereira A, Iqbal J, Ogawa S, Li Q \& Clarke IJ 2010 Kisspeptin cells in the ewe brain respond to leptin and communicate with neuropeptide $\mathrm{Y}$ and proopiomelanocortin cells. Endocrinology 151 2233-2243. (doi:10.1210/en.2009-1190)

Batool A, Naz R, Wazir M, Azam A, Ullah R, Wahab F \& Shahab M 2014 Acute fasting-induced repression of the hypothalamic-pituitary-gonadal axis is reversed by RF-9 administration in the adult male macaque. Hormone and Metabolic Research 46 927-832. (doi:10.1055/s-0034-1387788)
Beale KE, Kinsey-Jones JS, Gardiner JV, Harrison EK, Thompson EL, Hu MH, Sleeth ML, Sam AH, Greenwood HC, McGavigan AK et al. 2014 The physiological role of arcuate kisspeptin neurons in the control of reproductive function in female rats. Endocrinology 155 1091-1098. (doi:10.1210/en.2013-1544)

Castellano JM, Navarro VM, Fernandez-Fernandez R, Nogueiras R, Tovar S, Roa J, Vazquez MJ, Vigo E, Casanueva FF, Aguilar E et al. 2005 Changes in hypothalamic KiSS-1 system and restoration of pubertal activation of the reproductive axis by kisspeptin in undernutrition. Endocrinology 146 3917-3925. (doi:10.1210/en.2005-0337)

Castellano JM, Navarro VM, Fernández-Fernández R, Castaño JP, Malagón MM, Aguilar E, Dieguez C, Magni P, Pinilla L \& TenaSempere M 2006 Ontogeny and mechanisms of action for the stimulatory effect of kisspeptin on gonadotropin-releasing hormone system of the rat. Molecular and Cellular Endocrinology 257-258 75-83. (doi:10.1016/j.mce.2006.07.002)

Clarke IJ, Smith JT, Henry BA, Oldfield BJ, Stefanidis A, Millar RP, Sari IP, Chng K, Fabre-Nys C, Caraty A et al. 2012 Gonadotropin-inhibitory hormone is a hypothalamic peptide that provides a molecular switch between reproduction and feeding. Neuroendocrinology 95 305-316. (doi:10.1159/000332822)

De Bond JA \& Smith JT 2014 Kisspeptin and energy balance in reproduction. Reproduction 147 R53-R63. (doi:10.1530/REP-13-0509)

Ducret E, Anderson GM \& Herbison AE 2009 RFamide-related peptide-3, a mammalian gonadotropin-inhibitory hormone ortholog, regulates gonadotropin-releasing hormone neuron firing in the mouse. Endocrinology 150 2799-2804. (doi:10.1210/en.2008-1623)

Fu LY \& van den Pol AN 2010 Kisspeptin directly excites anorexigenic proopiomelanocortin neurons but inhibits orexigenic neuropeptide $Y$ cells by an indirect synaptic mechanism. Journal of Neuroscience $\mathbf{3 0}$ 10205-10219. (doi:10.1523/JNEUROSCI.2098-10.2010)

Funes S, Hedrick JA, Vassileva G, Markowitz L, Abbondanzo S, Golovko A, Yang S, Monsma FJ \& Gustafson EL 2003 The KiSS-1 receptor GPR54 is essential for the development of the murine reproductive system. Biochemical and Biophysical Research Communications 312 1357-1363. (doi:10.1016/j.bbrc.2003.11.066)

García-Galiano D, van Ingen Schenau D, Leon S, Krajnc-Franken MA, Manfredi-Lozano M, Romero-Ruiz A, Navarro VM, Gaytan F, van Noort PI, Pinilla L et al. 2012 Kisspeptin signaling is indispensable for neurokinin B, but not glutamate, stimulation of gonadotropin secretion in mice. Endocrinology 153 316-328. (doi:10.1210/en.2011-1260)

Glanowska KM, Burger LL \& Moenter SM 2014 Development of gonadotropinreleasing hormone secretion and pituitary response. Journal of Neuroscience 34 15060-15069. (doi:10.1523/JNEUROSCI.2200-14.2014)

Han SK, Gottsch ML, Lee KJ, Popa SM, Smith JT, Jakawich SK, Clifton DK, Steiner RA \& Herbison AE 2005 Activation of gonadotropin-releasing hormone $(\mathrm{GnRH})$ neurons by kisspeptin as a neuroendocrine switch for the onset of puberty. Journal of Neuroscience 25 11349-11356. (doi:10. 1523/JNEUROSCI.3328-05.2005)

Hinuma S, Shintani $\mathrm{Y}$, Fukusumi S, lijima N, Matsumoto $\mathrm{Y}$, Hosoya $\mathrm{M}$, Fujii R, Watanabe T, Kikuchi K, Terao Y et al. 2000 New neuropeptides containing carboxy-terminal RFamide and their receptor in mammals. Nature Cell Biology 2 703-708. (doi:10.1038/35036326)

Jacobi JS, Martin C, Nava G, Jeziorski MC, Clapp C \& Martínez de la Escalera G 2007 17- $\beta$-estradiol directly regulates the expression of adrenergic receptors and kisspeptin/GPR54 system in GT1-7 GnRH neurons. Neuroendocrinology 86 260-269. (doi:10.1159/000107770)

Johnson MA, Tsutsui K \& Fraley GS 2007 Rat RFamide-related peptide-3 stimulates $\mathrm{GH}$ secretion, inhibits $\mathrm{LH}$ secretion, and has variable effects on sex behavior in the adult male rat. Hormones and Behavior $\mathbf{5 1}$ 171-180. (doi:10.1016/j.yhbeh.2006.09.009)

Kelestimur H, Kacar E, Uzun A, Ozcan M \& Kutlu S 2013 Arg-Phe-amiderelated peptides influence gonadotropin-releasing hormone neurons. Neural Regeneration Research 8 1714-1720. (doi:10.3969/j.issn.16735374.2013.18.009)

Kotani $M$, Detheux $M$, Vandenbogaerde $A$, Communi D, Vanderwinden JM, Le Poul E, Brezillon S, Tyldesley R, SuarezHuerta N, Vandeput F et al. 2001 The metastasis suppressor gene KiSS-1 encodes kisspeptins, the natural ligands of the orphan Gprotein coupled receptor GPR54. Journal of Biological Chemistry 276 34631-34631. (doi:10.1074/jbc.M104847200) 
Kriegsfeld LJ, Mei DF, Bentley GE, Ubuka T, Mason AO, Inoue K, Ukena K, Tsutsui K \& Silver R 2006 Identification and characterization of a gonadotropin-inhibitory system in the brains of mammals. PNAS $\mathbf{1 0 3}$ 2410-2415. (doi:10.1073/pnas.0511003103)

Kroll H, Bolsover S, Hsu J, Kim SH \& Bouloux PM 2011 Kisspeptin-evoked calcium signals in isolated primary rat gonadotropin- releasing hormone neurones. Neuroendocrinology 93 114-120. (doi:10.1159/000321678)

Liu X \& Herbison AE 2014 RF9 excitation of GnRH neurons is dependent upon Kiss1r in the adult male and female mouse. Endocrinology 155 4915-4924. (doi:10.1210/en.2014-1517)

Maletinská L, Tichá A, Nagelová V, Spolcová A, Blechová M, Elbert T \& Zelezná B 2013 Neuropeptide FF analog RF9 is not an antagonist of NPFF receptor and decreases food intake in mice after its central and peripheral administration. Brain Research 1498 33-40. (doi:10.1016/j.brainres. 2012.12.037)

Matsui H, Takatsu Y, Kumano S, Matsumoto H \& Ohtaki T 2004 Peripheral administration of metastin induces marked gonadotropin release and ovulation in the rat. Biochemical and Biophysical Research Communications 320 383-388. (doi:10.1016/j.bbrc.2004.05.185)

Messager S, Chatzidaki EE, Ma D, Hendrick AG, Zahn D, Dixon J, Thresher RR, Malinge I, Lomet D, Carlton MB et al. 2005 Kisspeptin directly stimulates gonadotropin-releasing hormone release via G protein-coupled receptor 54. PNAS 102 1761-1766. (doi:10.1073/ pnas.0409330102)

Muir Al, Chamberlain L, Elshourbagy NA, Michalovich D, Moore DJ, Calamari A, Szekeres PG, Sarau HM, Chambers JK, Murdock P et al. 2001 AXOR12, a novel human G protein-coupled receptor, activated by the peptide KiSS-1. Journal of Biological Chemistry 276 28969-28975. (doi:10.1074/jbc.M102743200)

Navarro VM, Fernández-Fernández R, Castellano JM, Roa J, Mayen A, Barreiro ML, Gaytan F, Aguilar E, Pinilla L, Dieguez C et al. 2004 Advanced vaginal opening and precocious activation of the reproductive axis by KiSS-1 peptide, the endogenous ligand of GPR54. Journal of Physiology 561 379-386. (doi:10.1113/jphysiol.2004.072298)

Novaira HJ, Ng Y, Wolfe A \& Radovick S 2009 Kisspeptin increases GnRH mRNA expression and secretion in GnRH secreting neuronal cell lines. Molecular and Cellular Endocrinology 311 126-134. (doi:10.1016/j. mce.2009.06.011)

Ohtaki T, Shintani Y, Honda S, Matsumoto H, Hori A, Kanehashi K, Terao Y, Kumano S, Takatsu Y, Masuda Y et al. 2001 Metastasis suppressor gene KiSS-1 encodes peptide ligand of a G-protein-coupled receptor. Nature 411 613-617. (doi:10.1038/35079135)

Oishi S, Misu R, Tomita K, Setsuda S, Masuda R, Ohno H, Naniwa Y, leda N, Inoue N, Ohkura S et al. 2010 Activation of neuropeptide FF receptors by kisspeptin receptor ligands. ACS Medicinal Chemistry Letters 25 53-57. (doi:10.1021/ml1002053)

Ozcan M, Alcin E, Ayar A, Yilmaz B, Sandal S \& Kelestimur H 2011 Kisspeptin-10 elicits triphasic cytosolic calcium responses in immortalized GT1-7 GnRH neurones. Neuroscience Letters 492 55-58. (doi:10. 1016/j.neulet.2011.01.054)

Parhar IS, Ogawa S \& Sakuma Y 2004 Laser-captured single digoxigeninlabeled neurons of gonadotropin-releasing hormone types reveal a novel G protein-coupled receptor (GPR54) duringmaturation in cichlid fish. Endocrinology 145 3613-3618. (doi:10.1210/en.2004-0395)

Paxinos G \& Watson C 1998 The Rat Brain in Stereotaxic Coordinates, 4th edn. New York, NY: Academic Press.

Pineda R, Garcia-Galiano D, Sanchez-Garrido MA, Romero M, RuizPino F, Aguilar E, Dijcks FA, Blomenrohr M, Pinilla L, van Noort PI et al. 2010a Characterization of the potent gonadotropin-releasing activity of RF9, a selective antagonist of RF-amide-related peptides and neuropeptide FF receptors: physiological and pharmacological implications. Endocrinology 151 1902-1913. (doi:10.1210/en.20091259)

Pineda R, Garcia-Galiano D, Roseweir A, Romero M, SanchezGarrido MA, Ruiz-Pino F, Morgan K, Pinilla L, Millar RP \& TenaSempere M 2010b Critical roles of kisspeptins in female puberty and preovulatory gonadotropin surges as revealed by a novel antagonist. Endocrinology 151 722-730. (doi:10.1210/en.2009-0803)

Roa J \& Tena-Sempere M 2014 Connecting metabolism and reproduction: roles of central energy sensors and key molecular mediators. Molecular and Cellular Endocrinology 397 4-14. (doi:10.1016/j.mce. 2014.09.027)
Roseweir AK, Kauffman AS, Smith JT, Guerriero KA, Morgan K, PieleckaFortuna J, Pineda R, Gottsch ML, Tena-Sempere M, Moenter SM et al. 2009 Discovery of potent kisspeptin antagonists delineate physiological mechanisms of gonadotropin regulation. Journal of Neuroscience $\mathbf{2 9}$ 3920-3929. (doi:10.1523/JNEUROSCI.5740-08.2009)

de Roux N, Genin E, Carel JC, Matsuda F, Chaussain JL \& Milgrom E 2003 Hypogonadotropic hypogonadism due to loss of function of the KiSS1derived peptide receptor GPR54. PNAS 100 10972-10976. (doi:10. 1073/pnas.1834399100)

Seminara SB, Messager S, Chatzidaki EE, Thresher RR, Acierno JS Jr, Shagoury JK, Bo-Abbas Y, Kuohung W, Schwinof KM, Hendrick AG et al. 2003 The GPR54 gene as a regulator of puberty. New England Journal of Medicine 349 1614-1627. (doi:10.1056/NEJMoa035322)

Simonin F, Schmitt $M$, Laulin JP, Laboureyras $E$, Jhamandas JH, MacTavish D, Matifas A, Mollereau C, Laurent P, Parmentier M et al. 2006 RF9, a potent and selective neuropeptide FF receptor antagonist, prevents opioid-induced tolerance associated with hyperalgesia. PNAS 103 466-471. (doi:10.1073/pnas.0502090103)

Smith JT \& Clarke IJ 2010 Gonadotropin inhibitory hormone function in mammals. Trends in Endocrinology and Metabolism 21 255-260. (doi:10.1016/j.tem.2009.11.010)

Son YL, Ubuka T, Millar RP, Kanasaki H \& Tsutsui K 2012 Gonadotropininhibitory hormone inhibits GnRH-induced gonadotropin subunit gene transcriptions by inhibiting AC/CAMP/PKA-dependent ERK pathway in L $\beta T 2$ cells. Endocrinology 153 2332-2343. (doi:10.1210/en.2011-1904)

Stengel A, Wang L, Goebel-Stengel M \& Tache Y 2011 Centrally injected kisspeptin reduces food intake by increasing meal intervals in mice. Neuroreport 22 253-257. (doi:10.1097/WNR.0b013e32834558df)

Thompson EL, Patterson M, Murphy KG, Smith KL, Dhillo WS, Todd JF, Ghatei MA \& Bloom SR 2004 Central and peripheral administration of kisspeptin-10 stimulates the hypothalamic-pituitary-gonadal axis. Journal of Neuroendocrinology 16 850-858. (doi:10.1111/j.1365-2826.2004.01240.x)

Tolson KP, Garcia C, Yen S, Simonds S, Stefanidis A, Lawrence A, Smith JT \& Kauffman AS 2014 Impaired kisspeptin signaling decreases metabolism and promotes glucose intolerance and obesity. Journal of Clinical Investigation 124 3075-3079. (doi:10.1172/JCl71075)

Tonsfeldt KJ, Goodall CP, Latham KL \& Chappell PE 2011 Oestrogen induces rhythmic expression of the kisspeptin-1 receptor GPR54 in hypothalamic gonadotrophin-releasing hormone-secreting GT1-7 cells. Journal of Neuroendocrinology 23 823-830. (doi:10.1111/j.1365-2826. 2011.02188.x)

Tsutsui K 2009 A new key neurohormone controlling reproduction, gonadotropin-inhibitory hormone $(\mathrm{GnlH})$ : biosynthesis, mode of action and functional significance. Progress in Neurobiology 88 76-88. (doi:10. 1016/j.pneurobio.2009.02.003)

Tsutsui K, Saigoh E, Ukena K, Teranishi H, Fujisawa Y, Kikuchi M, Ishii S \& Sharp PJ 2000 A novel avian hypothalamic peptide inhibiting gonadotropin release. Biochemical and Biophysical Research Communications 275 661-667. (doi:10.1006/bbrc.2000.3350)

Ubuka T, Morgan K, Pawson AJ, Osugi T, Chowdhury VS, Minakata H, Tsutsui K, Millar RP \& Bentley GE 2009 Identification of human GnlH homologs, RFRP-1 and RFRP-3, and the cognate receptor, GPR147 in the human hypothalamic pituitary axis. PLOS ONE 4 e8400. (doi:10.1371/ journal.pone.0008400)

Ubuka T, Inoue K, Fukuda Y, Mizuno T, Ukena K, Kriegsfeld LJ \& Tsutsui K 2012 Identification, expression, and physiological functions of siberian hamster gonadotropin-inhibitory hormone. Endocrinology 153 373-385. (doi:10.1210/en.2011-1110)

Wu M, Dumalska I, Morozova E, van den Pol AN \& Alreja M 2009 Gonadotropin inhibitory hormone inhibits basal forebrain vGluT2gonadotropin-releasing hormone neurons via a direct postsynaptic mechanism. Journal of Physiology 587 1401-1411. (doi:10.1113/ jphysiol.2008.166447)

Received 30 December 2014

First decision 26 January 2015

Revised manuscript received 1 February 2015

Accepted 23 February 2015 